\title{
Endometriosis and Susceptibility to Cancer: The Dark Side of IFN- $\gamma$ Gene Polymorphism?
}

\section{Raffaella Mormile ${ }^{1 *}$ and Giorgio Vittori ${ }^{2}$}

${ }^{1}$ Division of Pediatrics and Neonatology, Moscati Hospital, Aversa, Italy

${ }^{2}$ Division of Gynecology - San Carlo di Nancy Hospital - Rome, Italy

Endometriosis is a chronic condition characterized by the growth of endometrial-like tissue outside the uterus [1]. The prevalence of endometriosis has been connected with ethnicity in a range of potential genetic and environmental risk factors ${ }^{1}$. Endometriosis generally follows a benign course [2]. However, it is at risk for transforming and becoming cancer [2-5]. Endometriosis, like cancer, is characterized by pathogenic mechanisms such as cell invasion, unrestrained growth, decreased apoptosis and development of new vessels from the existing vasculature in a process called angiogenesis [3]. In spite of these similarities, endometriosis is not described as a malignant condition [3]. The possibility that endometriosis could evolve in cancerous transformation has been postulated in the literature since 1925 [3]. To date the exact molecular mechanisms that may lead to the malignant transformation of endometriosis have not been fully defined [4]. Data have suggested that mutations in the PTEN (phosphatase and tensin homolog deleted on chromosome 10) gene may play an important role in the cancerous transformation of endometriosis [4-7]. PTEN is a tumour suppressor commonly mutated in many human cancers [8]. Progressive loss of PTEN or accumulation of mutations in the PTEN gene has been related to advancing cancer [7]. Conversely, overexpression of PTEN has been linked to the suppression of tumorigenicity and cell growth $[7,8]$. In addition, it has been reported that racial disparity in the frequency of PTEN mutations may contribute to the ethnic differences in cancer survival [6]. It has been found that PTEN acts as a tumour suppressor by directly antagonizing the activity of phosphoinositide 3-kinase (PI3K) pathway $[7,8]$. The active form of $\mathrm{PI} 3 \mathrm{~K}$ is an oncogene $[7,8]$. AKT and mTor are important downstream targets of PI3K . Amplifications and mutations of PI3K have been connected with the most common human cancers [7-9]. It has been shown that mutations in the gene encoding the p110a subunit of PI3K activity coupled with PTEN loss are enough to promote tumorigenesis ${ }^{8}$. The PI3K/PTEN pathway controls multiple cellular functions such as cell metabolism, proliferation, cell-cycle progression and survival [7]. Moreover, the PI3K-PTEN axis regulates angiogenesis by inducing vascular endothelial growth factor (VEGF) expression [7]. Angiogenesis is essential for tumour growth and metastasis [9]. PTEN can be upregulated by early growth regulated transcription factor 1 (EGR1) through direct binding to the PTEN promoter $[9,10]$. The transcription factor EGR1 is a direct regulator of multiple tumour suppressor $[9,10]$. However, it is enganged in proapoptotic or prosurvival signals, depending on the cellular contest [8-10]. It has been written that EGR1 is a downstream target of epidermal growth factor receptor (EGFR) through the mitogen-activated protein kinase (MAPK) signaling pathways [10]. Indeed, its overexpression is able to preserve cell viability in presence of EGFR inhibitors [10]. Intriguingly, it has been proved that EGF functional polymorphism may influence cancer prognosis through an EGF/EGFR pathway [11]. Similarly to EGR1, PI3K is also activated by EGFR [9]. Interestingly, a crosstalk between MAPK and PI3K has been proposed in cancer [12]. Prolonged MAPK activity has been associated with interferon- $\gamma($ IFN- $\gamma)$ [13]. That is a cytokine whose biological activity is conventionally related to cytostatic/cytotoxic and antitumor mechanisms during cell-mediated adaptive immune response [13]. However, it has been found that IFN- $\gamma$ may also have protumorigenic effects under certain circumstances [14]. In this contest, it has been shown that IFN- $\gamma$ gene polymorphism may contribute to cancer susceptibility [15]. Oncogenic activation evolves mechanisms to escape immune surveillance by a process called immune editing which provides a selective pressure in the tumour microenvironment leading to malignant progression [16]. In this respect, IFN- $\gamma$ resistance is considered critical for cancer cell growth and survival $[16,17]$. Notably, it has been shown that PI3K/AKT alone mediates the IFN- $\gamma$ resistance [17]. What is more, reduction of PTEN activity seems to be essential for IFN- $\gamma$ resistance and hyperproliferation of cancer cells [17]. Interestingly, it has been demonstrated that enhanced lymphocyte interferon (IFN)- $\gamma$ may influence the PI3K/ mTor causal molecular pathway in a PTEN mutation-negative cancer syndrome [18]. It is widely accepted that endometriosis is a chronic inflammatory process with abnormalities in INF- $\gamma$ production $[1,19,20]$. IFN- $\gamma$ gene polymorphism has been linked to different stages of endometriosis with interethnic differences across many countries $[19,20]$. Intriguingly, endometriotic cells are resistant to IFN- $\gamma$ induced cell growth inhibition and apoptosis [21]. Although the precise mechanism leading to IFN- $\gamma$ resistance is still unidentified, it has been supposed the existence of dysregulation of intracellular signaling pathways in endometriotic stromal cells [21]. On this regard, IFN- $\gamma$ has been described to activate EGF system and to modulate EGF activation of downstream signaling pathways [22]. The expression of EGF system in eutopic endometrium from women with endometriosis varies from healthy women with important quantitative and qualitative differences [23]. It has been provided the direct evidence of the dependence of IFN- $\gamma$-induced EGFR transactivation upon EGFR expression level in epithelial cells [24]. VEGF has also been strongly associated with the pathophysiology of endometriosis [25]. IFN- $\gamma$ is considered an indirect inducer of angiogenesis through the activation of VEGF [26,27]. In particular, IFN- $\gamma$ has been reported to regulate VEGF production by endometrial stromal cells in a dose-dependent manner [27]. EGR1 has also been related to endometriosis [28]. Interestingly, it has been demonstrated that IFN- $\gamma$ may regulate EGR1 gene expression [29]. Intriguingly, MAPK signaling pathway has been involved directly in regulating the pathogenesis of endometriosis [30,31]. Attractively, IFN- $\gamma$ has been correlated with MAPK that has been reported to exert influence on both PI3K and EGR1 $[10,13]$. Taken together, we speculate

*Corresponding author: Raffaella Mormile - Division of Pediatrics and Neonatology - Moscati Hospital - Via A. Gramsci, 3 - 81031 Aversa, Italy, Tel: +393392045468; E-mail: raffaellamormile@alice.it

Received May 26, 2013; Accepted July 18, 2013; Published July 22, 2013

Citation: Mormile R, Vittori G (2013) Endometriosis and Susceptibility to Cancer: The Dark Side of IFN-y Gene Polymorphism? J Cancer Sci Ther 5: 289-290. doi:10.4172/1948-5956.1000218

Copyright: ( $) 2013$ Mormile R, et al. This is an open-access article distributed under the terms of the Creative Commons Attribution License, which permits unrestricted use, distribution, and reproduction in any medium, provided the original author and source are credited. 
that susceptibility to cancer in endometriosis may be correlated with ethnicity-related IFN- $\gamma$ gene polymorphism that deregulates the functional network of suppressor factors that serve to maintain normal growth regulation. We advance the hypotheses that IFN- $\gamma$ gene polymorphism may mediate PTEN activity deregulation, independently of the type of PTEN mutation, via upregulation of PI3K pathway and downregulation of EGR1 through MAPK. Furthermore, IFN gene polymorphism may influence EGFR and may be responsible for the VEGF-mediated neovascularization pathway involved in the pathogenesis of endometriosis and cancer. All these contentions led us to suppose that downstream signaling pathways induced by IFN- $\gamma$ variants may display multiple nodes of interaction with each other implying that perturbation of any of the tumor suppressors may cause some degree of dysfunction of the others resulting in the molecular differences in the setting of severe versus mild endometriosis and in the malignant transformation of endometriosis. IFN- $\gamma$ gene polymorphism should be assessed as well as its geographic and population heterogeneities due to racial admixture. The use of racially determined polymorphisms of IFN- $\gamma$ gene as biomarkers of neoplastic transformation in genetic counseling screening might provide an opportunity to identify women with endometriosis at increased risk of cancer. For women with an allele associated with cancer development and progression, knowing that they have such a mutation may be helpful in order to adopt prevention strategies from adolescence to adulthood. Furthermore, a more detailed understanding of INF- $\gamma /$ PI3K/EGR-1/PTEN signaling axis may represent a target for the development of novel diagnostic and therapeutic strategies for both endometriosis and cancer worldwide. Genomic and proteomic studies are needed to clarify the components of the potential machinery leading to cancer by IFN- $\gamma$ gene polymorphism in endometriosis.

\section{References}

1. Gerlinger C, Faustmann T, Hassall JJ, Seitz C (2012) Treatment of endometriosis in different ethnic populations: a meta-analysis of two clinical trials. BMC Womens Health 12: 9 .

2. Martini M, Ciccarone M, Garganese G, Maggiore C, Evangelista A, et al (2002) Possible involvement of hMLH1, p16(INK4a) and PTEN in the malignant transformation of endometriosis. Int J Cancer 102: 398-406.

3. Swiersz LM (2002) Role of endometriosis in cancer and tumor development. Ann N Y Acad Sci 955: 281-292.

4. Gemmill JA, Stratton P, Cleary SD, Ballweg ML, Sinaii N (2010) Cancers, infections, and endocrine diseases in women with endometriosis. Fertil Steril 94: 1627-1631

5. Munksgaard PS, Blaakaer J (2012) The association between endometriosis and ovarian cancer: a review of histological, genetic and molecular alterations. Gynecol Oncol 124: 164-169.

6. Maxwell GL, Risinger JI, Hayes KA, Alvarez AA, Dodge RK, et al. (2000) Racial disparity in the frequency of PTEN mutations, but not microsatellite instability, in advanced endometrial cancers. Clin Cancer Res 6: 2999-3005.

7. Sansal I, Sellers WR (2004) The biology and clinical relevance of the PTEN tumor suppressor pathway. J Clin Oncol 22: 2954-2963.

8. Kinross KM, Montgomery KG, Kleinschmidt M, Waring P, Ivetac I, et al. (2012) An activating Pik3ca mutation coupled with Pten loss is sufficient to initiate ovarian tumorigenesis in mice. J Clin Invest 122: 553-557.

9. Jiang BH, Liu LZ (2009) PI3K/PTEN signaling in angiogenesis and tumorigenesis. Adv Cancer Res 102: 19-65.

10. Voena C, Di Giacomo F, Panizza E, D'Amico L, Boccalatte FE, et al. (2013) The EGFR family members sustain the neoplastic phenotype of ALK+ lung adenocarcinoma via EGR1. Oncogenesis 2: e43.

11. Araújo AP, Catarino R, Ribeiro R, Pereira D, Pinto D, et al. (2012) Epiderma growth factor genetic variation associated with advanced cervical cancer in younger women. Am J Clin Oncol 35: 247-250.
12. Carracedo A, Pandolfi PP (2008) The PTEN-PI3K pathway: of feedbacks and cross-talks. Oncogene 27: 5527-5541.

13. Valledor AF, Arpa L, Sánchez-Tilló E, Comalada M, Casals C, et al. (2008) IFN-\{gamma\}-mediated inhibition of MAPK phosphatase expression results in prolonged MAPK activity in response to M-CSF and inhibition of proliferation. Blood 112: 3274-3282.

14. Zaidi MR, Merlino G (2011) The two faces of interferon- $\left.\right|^{3}$ in cancer. Clin Cancer Res 17: 6118-6124.

15. Mi YY, Yu QQ, Xu B, Zhang LF, Min ZC, et al. (2011) Interferon gamma +874 T/A polymorphism contributes to cancer susceptibility: a meta-analysis based on 17 case-control studies. Mol Biol Rep 38: 4461-4467.

16. Kim R, Emi M, Tanabe K (2007) Cancer immunoediting from immune surveillance to immune escape. Immunology 121: 1-14

17. Tseng PC, Huang WC, Chen CL, Sheu BS, Shan YS, et al. (2012) Regulation of SHP2 by PTEN/AKT/GSK-3 $\hat{I}^{2}$ signaling facilitates IFN- $\hat{I}^{3}$ resistance in hyperproliferating gastric cancer. Immunobiology 217: 926-934.

18. Stevenson R, Fatehullah A, Jagan I, Deevi RK (2011) Enhanced lymphocyte interferon (IFN)-y responses in a PTEN-mutation-negative Cowden disease kindred. Clinical and Experimental Immunology 164: 202-210.

19. Bhanothu V, Rozati R, Theophilus J (2013) Prevalence and polymorphism in interferon-? Gene (CA) repeats with different stage of endometriosis. Am J Med Biol Res 1: 1-5.

20. Guo S, Zhang Y, Wang L, Qiu W (2012) [Association of natural killer T cells with staging of endometriosis]. Nan Fang Yi Ke Da Xue Xue Bao 32: 1322-1324.

21. Nishida M, Nasu K, Ueda T, Fukuda J (2004) Endometriotic cells are resistan to interferon-?-induced cell growth inhibition and apoptosis: a possible mechanism involved in the pathogenesis of endometriosis. Molecular Human Reproduction 11: 29-34.

22. Marchelletta PG, McCole DF, Barrett KE (2012) Interferon-y alters downstream signaling originating from epidermal growth factor receptor in intestinal epithelia cells: functional consequences for ion transport. J Biol Chem 287:2144-55.

23. Ejskjaer K, Sorensen BS, Poulsen SS, Mogensen O, Forman A, et al. (2009) Expression of the epidermal growth factor system in eutopic endometrium from women with endometriosis differs from that in endometrium from healthy women. Gynecol Obstet Invest 67: 118-126.

24. Gonchar IV, Dorosh VN, Nikol'skiÄ NN, Burova EB (2008) [The level of EGF receptor expression effects its transactivation by IFN gamma in epithelial cells] Tsitologiia 50: 887-892.

25. Vanaja MC, Rozati R, Nassaruddin K, Vishnupriya S (2013) Association of VEGF $+405 \mathrm{G}>\mathrm{C}$ polymorphism with endometriosis. Front Biosci (Elite Ed) 5 748-754.

26. Paine SK, Basu A, Mondal LK, Sen A, Choudhuri S, et al. (2012) Association of vascular endothelial growth factor, transforming growth factor beta, and interferon gamma gene polymorphisms with proliferative diabetic retinopathy in patients with type 2 diabetes. Mol Vis 18: 2749-2757.

27. Choi SJ, Park JY, Lee YK, Choi HI, Lee YS, et al. (2002) Effects of cytokines on VEGF expression and secretion by human first trimester trophoblast cell line. Am J Reprod Immunol 48: 70-76.

28. Kawano Y, Matsui N, Kamihigashi S, Narahara H, Miyakawa I (2000) Effects of interferon-gamma on secretion of vascular endothelial growth factor by endometrial stromal cells. Am J Reprod Immunol 43: 47-52.

29. Taylor RN, Lundeen SG, Giudice LC (2002) Emerging role of genomics in endometriosis research. Fertil Steril 78: 694-698.

30. Cao XM, Guy GR, Sukhatme VP, Tan YH (1992) Regulation of the Egr-1 gene by tumor necrosis factor and interferons in primary human fibroblasts. $\mathrm{J}$ Bio Chem 267: 1345-1349

31. Zhou WD, Chen QH, Chen QX (2010) [The action of p38 MAP kinase and its inhibitors on endometriosis]. Yao Xue Xue Bao 45: 548-554. 